\title{
PERAN ACCEPTANCE AND COMMITMENT THERAPY (ACT) UNTUK MENURUNKAN STRES PADA FAMILY CAREGIVER PASIEN KANKER PAYUDARA
}

\author{
Afifah Nuraini ${ }^{1}$, Nurul Hartini $\left.{ }^{*}\right)$ \\ ${ }^{1}$ Fakultas Psikologi, Universitas Airlangga, Surabaya 60286, Indonesia \\ *)E-mail: nurul.hartini@psikologi.unair.ac.id
}

\begin{abstract}
Abstrak
Ketidaksiapan keluarga terhadap perubahan peran menjadi caregiver, kurangnya pengetahuan terhadap prosedur perawatan, serta beban dan tanggung jawab terhadap perawatan pasien kanker payudara menyebabkan stres pada keluarga. Tujuan dari penelitian ini adalah untuk menganalisis pengaruh Acceptance and Commitment Therapy (ACT) terhadap penurunan stres pada family caregiver pasien kanker payudara. Penelitian ini menggunakan pendekatan eksperimen dengan single-subject design pada dua orang subjek penelitian. Sebelum proses terapi, masing-masing subjek diberikan skala perceived stress (PSS-10) untuk mengukur tingkat stres sebelum proses terapi kemudian pada setiap sesi terapi masing-masing subjek diberi skala perceived stress kembali untuk mengukur perubahan tingkat stres pada setiap sesinya. Analisis data menggunakan visual analisis, analisis inferensia untuk uji perbedaan dengan wilcoxon signed rank test, dan Percentage of Non-overlapping Data (PND) untuk mengetahui effect size. Hasil analisis data menunjukkan nilai effect size sebesar $1(>0,90)$ yang berarti ACT mampu menurunkan stres kedua subjek dengan kategori efektivitas sedang hingga sangat efektif. Melalui penerapan ACT, family caregiver mampu memaknai situasi stres dengan lebih positif sehingga muncul penerimaan dan komitmen yang baik dalam perannya sebagai caregiver pasien kanker payudara.
\end{abstract}

Kata kunci: family caregiver, kanker payudara, stres, terapi penerimaan, terapi komitmen

\section{The Role of Acceptance and Commitment Therapy (ACT) to Reduce Stress for Family Caregiver of Breast Cancer Patients}

\begin{abstract}
The family's unpreparedness towards the changing role as a caregiver, lack of knowledge of treatment procedures, and the burden and responsibility for caring for breast cancer patients causes stress to the family. The aim of this research was to examine the effectiveness of Acceptance and Commitment Therapy (ACT) to reduce stress on family caregivers of breast cancer patients. This research used an experimental approach with single-subject design on two research subjects. Before the therapy process, each subject was given a Perceived Stress Scale (PSS-10) to measure stress levels, then at each therapy session the Perceived Stress Scale was given again to measure changes in stress levels. We analyzed data using visual analysis, inferential analysis to test differences with the wilcoxon signed rank test, and Percentage of Non-overlapping Data (PND) to determine the effect size. The result of data analysis showed the effect size value of $1(>0,90)$ indicating that ACT was able to reduce stress experienced by subjects with the moderate to high effectiveness. With the provision of ACT, family caregivers are able to interpret the stress situasion more positively so encourage acceptance and commitment in their role as caregiver for breast cancer patients.
\end{abstract}

Keywords: acceptance therapy, breast cancer, commitment therapy, family caregiver, stress

\section{PENDAHULUAN}

Kanker merupakan penyakit yang disebabkan oleh pertumbuhan sel-sel jaringan tubuh yang tidak normal dan berubah menjadi sel kanker (Soemitro, 2012). Sel kanker dapat berkembang dan menyebar ke bagian tubuh lain sampai menyebabkan kematian. Kanker menjadi penyebab kematian terbanyak ketiga di
Indonesia setelah jantung dan stroke (Kemenkes, 2020). Data dari World Health Organization (WHO) tahun 2019 menyebutkan bahwa kasus kanker yang paling banyak terjadi di Indonesia adalah kanker payudara, yaitu sebanyak 58.256 kasus atau 16,7 persen dari total 348.809 kasus kanker. WHO (2019) juga mengungkapkan bahwa kanker payudara merupakan jenis kanker yang paling sering 
terjadi pada wanita serta menjadi penyebab kematian terbesar terkait kanker pada wanita. Data hasil riset menunjukkan bahwa ada 2,1 juta kasus kanker payudara setiap tahunnya dan pada tahun 2018 diperkirakan sebanyak 627.000 wanita meninggal karena kanker payudara.

Kanker payudara merupakan tumor ganas yang berawal di jaringan payudara (American Cancer Society, 2011). Soemitro (2012) menjelaskan bahwa kanker payudara terjadi akibat perubahan sel dan saluran kelenjar susu dalam payudara yang normal menjadi sel yang bersifat merusak. Sel ini tumbuh sangat cepat dibandingkan sel normal. Selain itu, sel ini juga memiliki sifat merusak jaringan sekitar payudara dan dapat menyebar ke kelenjar getah bening, masuk ke pembuluh darah hingga ke organ lain seperti tulang, paru-paru, lever/hati, bahkan otak, dan menyebabkan kegagalan fungsi organ-organ tersebut sehingga menyebabkan kematian. Soemitro (2012) menjelaskan bahwa terdapat beberapa cara yang dapat dilakukan sebagai upaya penanganan kanker payudara, yaitu operasi mastektomi, Breast Canserving Therapy (BCT), terapi radiasi, kemoterapi, dan terapi hormon.

Penanganan kanker payudara tidak hanya bertujuan untuk mengontrol kekambuhan melainkan juga untuk meningkatkan kualitas hidup pasien (Ramli, 2015). Soemitro (2012) menjelaskan penanganan pertama yang biasa dilakukan pada pasien kanker payudara adalah dengan tindakan operasi pengangkatan tumor di payudara, kemudian dilakukan pemeriksaan pada jaringan tersebut untuk memastikan jenis dan keganasannya. Jika tumor tergolong ganas, maka penanganan selanjutnya disesuaikan dengan tingkat keparahan atau stadiumnya. Soemitro (2012) juga mengemukakan bahwa tingkat keparahan dan pengobatan yang dijalani pasien kanker menyebabkan penurunan kondisi fisik dan perubahan reaksi emosi dari pasien. Pada tingkat keparahan atau stadium yang lebih tinggi (paliatif) dibutuhkan penanganan yang lebih intensif sehingga proses pengobatan tidak hanya dilakukan di rumah sakit atau pusat layanan kesehatan, namun juga perawatan di rumah tempat tinggal pasien.

Perawatan kesehatan pasien kanker tidak bisa dipisahkan dari peran caregiver. Seiring dengan perjalanan sakit pasien, seringkali pasien tidak mampu melakukan perawatan secara mandiri (Cantwell et al., 2000; Cassidy \& McLaughlin, 2015). Disaat kondisi pasien tidak mampu melakukan perawatan secara mandiri, maka caregiver berperan membantu pasien untuk melakukan perawatan luka pasca operasi, pemberian obat, menyediakan transportasi, mengelola keuangan, termasuk membantu kegiatan sehari-hari pasien seperti makan dan mandi, serta memberikan dukungan secara emosional dan spiritual (Bevans \& Strenberg, 2012). Caregiver merupakan seseorang yang memiliki hubungan pribadi seperti keluarga, teman atau kerabat yang secara khusus bersedia untuk membantu penderita penyakit kronis atau disabilitas. Caregiver dibedakan menjadi dua jenis, yaitu caregiver formal dan caregiver informal. Caregiver formal merupakan tenaga profesional yang memberikan perawatan di layanan kesehatan seperti klinik, rumah sakit, atau pusat layanan kesehatan lainnya. Sedangkan caregiver informal atau disebut pula family caregiver merupakan seseorang yang memberikan perawatan secara sukarela dan biasanya bukan tenaga profesional, yang mana perawatan oleh caregiver informal biasanya dilakukan di rumah oleh anggota keluarga (Family Caregiver Alliance, 2009). Family caregiver bisa merupakan perawat utama (primer) atau pendukung (sekunder) dan dapat tinggal bersama atau terpisah dengan pasien yang menerima perawatan (Weitzner, Haley, \& Chen, 2000). Cassidy dan McLaughlin (2015) dalam penelitiannya menyatakan bahwa proses perawatan pasien kanker yang melibatkan keluarga (family caregiver) memberikan dampak yang signifikan terhadap kondisi kesehatan pasien.

Family caregiver memiliki peran penting dalam manajemen pasien kanker untuk mencapai kesembuhan (Kohle et al., 2015). Family caregiver bekerja sama dengan tenaga kesehatan berupaya untuk meningkatkan kesehatan dan kualitas hidup pasien. Family caregiver membantu tenaga kesehatan mengawasi perubahan kondisi kesehatan pasien dan membuat keputusan terkait rencana tindakan perawatan dan pengobatan pasien (Familly Caregiver Alliace, 2009). Peran sebagai family caregiver menuntut seseorang untuk meluangkan waktu dan energi agar dapat fokus memberikan perawatan pada pasien (Son et al., 2007). Family caregiver sering mengabaikan perawatan diri sendiri, seperti kurang tidur, kurang makan, dan tidak berolahraga yang dapat berdampak pada permasalahan fisik dan mental mereka akibat beban perawatan (Stenberg, Ruland, \& Miaskowski, 2010). Bagi family caregiver, peran perawatan pasien dapat menimbulkan keluhan baik fisik maupun mental serta memengaruhi kualitas hidupnya. 
Selama proses perawatan dan pengobatan pasien kanker, family caregiver menunjukkan perubahan pada kesehatan fisiologis, psikologis, dan sosial (Sercekus et al., 2014). Family caregiver biasanya menyembunyikan perasaan negatif mereka dan menghindari pembahasan mengenai penyakit pasien karena mencemaskan perubahan respon pasien.

Lebih lanjut, Kim dan Schulz (2008) menjelaskan bahwa tingkat beban pengasuhan sebagai caregiver pasien kanker dan demensia lebih besar dibandingkan tingkat beban pengasuhan yang dialami oleh caregiver lansia. Pasien kanker yang menunjukkan penurunan kemampuan fungsional anggota tubuh, perubahan peran dalam keluarga, peran sosial, dan status pekerjaan dapat berdampak pada perubahan tujuan hidup family caregiver (Nijboer et al., 1998). Simtom caregiver burden menjadi risiko sebagai caregiver pasien kanker stadium akhir, stres yang dialami oleh family caregiver mengalami peningkatan seiring dengan perkembangan gejala dan keparahan dari pasien kanker (Palos et al., 2010). Beban pengasuhan atau caregiver burden yang lebih tinggi cenderung dialami oleh caregiver yang berpendidikan rendah, tinggal bersama dengan pasien penerima perawatan, dan tidak memiliki pilihan selain mengambil peran sebagai caregiver (Collins \& Swartz, 2011).

Beberapa faktor penyebab stres pada family caregiver pasien kanker, diantaranya berkaitan dengan masalah kesehatan fisik, keuangan, dan reaksi sosial emosional. Reaksi sosial emosional biasanya muncul ketika menerima kabar buruk dari tenaga kesehatan mengenai perkembangan penyakit pasien, persepsi, dan tingginya harapan masyarakat pada caregiver, serta hubungan dalam keluarga (Othman, Mahmud, dan Karim, 2019; Weitzner et al., 2000).

Menurut Stenberg et al. (2010), reaksi emosional yang muncul pada family caregiver dapat bersifat positif dan negatif. Reaksi emosional positif bisa berupa perasaan dibutuhkan, memiliki waktu yang berkualitas dengan pasien, mendapatkan pengetahuan baru, dan perasaan berharga. Sedangkan reaksi emosional negatif bisa berupa perasaan terbebani, khawatir, cemas, frustrasi, dan stres. Stres yang dialami oleh family caregiver merupakan hasil penilaiannya terhadap beban pengasuhan pasien kanker sebagai beban yang melebihi kapasitas dan mengancam kesejahteraan dirinya (Lazarus \& Folkman, 1984).
Situasi stres yang berkaitan dengan pengasuhan biasanya terjadi secara terusmenerus, tidak terkendali (uncontrollable), dan tidak dapat diprediksi (unpredictable). Beberapa gejala dan tanda stres yang dialami family caregiver pasien kanker, antara lain gejala fisik meliputi sakit kepala, nyeri otot, nyeri tulang belakang, dan kelelahan; gejala psikologis meliputi kebosanan, gangguan mood, perasaan takut, khawatir, dan perasaan terasing; serta gejala perilaku meliputi menunda atau menghindari pekerjaan, perilaku makan yang tidak normal, menarik diri dari lingkungan sosial, dan penurunan kualitas hubungan interpersonal (Collins \& Swartz, 2011). Dengan demikian, dibutuhkan intervensi psikologis untuk membantu family caregiver menurunkan stres sebagai dampak dari pengasuhan dan perawatan pada pasien kanker.

Peneliti di bidang psikologi kesehatan menyatakan bahwa intervensi untuk mengatasi stres adalah dengan memperkuat respon adaptif individu dan kemampuan kognitifnya dalam menghadapi stres (Borji et al., 2018; Riskind \& Alloy, 2006). Salah satu pendekatan yang menekankan pada kesadaran dalam menghadapi stres adalah Acceptance and Commitment Therapy (ACT). ACT merupakan generasi baru dari terapi perilaku kognitif (cognitive behavioral) yang menggunakan konsep penerimaan, kesadaran, dan penggunaan nilai-nilai individu untuk menghadapi stresor jangka panjang (Hayes et al., 2006). Melalui konsep tersebut, individu dapat mengidentifikasi pikiran dan perasaan, menerima kondisi dan perubahan yang terjadi, serta berkomitmen meskipun mendapati pengalaman atau situasi yang tidak menyenangkan.

ACT adalah bentuk psikoterapi yang mendorong individu untuk menerima peristiwa seperti pikiran, perasaan, atau ingatan yang tidak diinginkan dengan suatu proses terstruktur untuk memberikan makna pada kehidupan mereka (Davis, Deane, \& Lyons, 2015; Harris, 2006). Hayes et al. (2011) menjelaskan bahwa ACT bertujuan untuk mengubah hubungan antara individu dengan peristiwa yang tidak diinginkannya. Pada family caregiver, ACT dapat mengubah hubungan antara family caregiver dengan situasi stres pengasuhan dan perawatan pasien sehingga tidak menganggap perubahan perannya sebagai sesuatu yang perlu dihindari atau dihilangkan, melainkan diterima sebagai pengalaman psikologis yang bernilai dan tidak menimbulkan bahaya. 
Beberapa penelitian sebelumnya telah menguji efektivitas ACT pada caregiver. Penelitian Losada et al. (2015) yang membandingkan efektivitas Cognitive Behavioral Therapy (CBT) dengan Acceptance and Commitment Therapy (ACT) pada family caregiver pasien demensia menunjukkan bahwa ACT terbukti lebih unggul untuk mengurangi stres secara statistik dan klinis yang berkaitan dengan simtom depresi dan kecemasan. Penelitian lain dilakukan Kohle et al. (2015), menunjukkan bahwa ACT terbukti efektif dalam mengatasi permasalahan yang berkaitan dengan sistem perawatan (caregiving) dan dapat diberikan pada keluarga atau pasangan pasien kanker yang membutuhkan dukungan. ACT mampu membantu caregiver pasien kanker dalam menghadapi emosi negatif yang dirasakan seperti kesedihan, cemas, ketidakpastian, dan kemarahan dibanding menghindarinya. Sejalan dengan penelitian tersebut, penelitian yang dilakukan oleh Davis et al. (2019) mengenai efektivitas ACT pada caregiver pasien paliatif menunjukkan bahwa ACT membantu caregiver memaknai kehidupannya dengan lebih positif, serta mampu melewati kesedihan dan tekanan psikologis. Hasil penelitian tersebut mendukung pernyataan Kim dan Schulz (2008) bahwa family caregiver yang dapat memaknai pengalamannya sebagai caregiver secara positif akan memiliki tingkat stres yang lebih rendah dan kualitas hidup yang lebih baik.

Berdasarkan penelitian sebelumnya tentang ACT dalam mengatasi tekanan psikologis yang dihadapi oleh caregiver pasien kanker, peneliti juga akan menerapkan ACT untuk membantu menurunkan stres family caregiver pasien kanker payudara. Diharapkan melalui intervensi ini, family caregiver mampu meningkatkan fleksibilitas dalam menghadapi stresor dan memaknai setiap pengalamannya dalam mendampingi perawatan dan pengobatan pasien kanker payudara dengan lebih positif sehingga family caregiver dapat menunjukkan perilaku yang lebih adaptif. Dengan demikian, penelitian ini bertujuan untuk menganalisis pengaruh Acceptance and Commitment Therapy (ACT) terhadap penurunan stres pada family caregiver pasien kanker payudara. Perbedaan penelitian ini dengan penelitian sebelumnya adalah peneliti akan menggambarkan dinamika psikologis family caregiver pasien kanker payudara.

\section{METODE}

Penelitian ini menggunakan metode penelitian eksperimen dengan single-subject design. Menurut Sunanto, Takeuchi, dan Nakata
(2005), single-subject design menggunakan pengukuran variabel terikat atau target perilaku yang dilakukan secara berulang-ulang dengan periode waktu tertentu, misalnya setiap minggu, hari, atau jam. Penelitian dengan desain ini melakukan perbandingan antara fase baseline dengan sekurang-kurangnya satu fase intervensi. Subjek dalam penelitian ini berjumlah dua orang family caregiver pasien kanker payudara yang memenuhi kriteria subjek penelitian dan telah menyatakan kesediaan secara sukarela dengan menandatangani informed consent. Kegiatan intervensi dilakukan pada rentang waktu bulan Juni hingga Agustus 2020 di rumah masingmasing subjek yang berlokasi di Surabaya dan Sidoarjo, Jawa Timur. Intervensi dilakukan secara individual karena intervensi dilaksanakan saat pandemi Covid-19; intervensi dilakukan dengan menerapkan protokol kesehatan.

Penelitian ini menggunakan teknik purposive sampling untuk menentukan subjek penelitian. Menurut Neuman (2006), teknik purposive sampling dapat digunakan pada kasus yang unik, populasi yang sulit dijangkau, dan untuk identifikasi kasus secara mendalam. Subjek pada penelitian ini ditetapkan dengan kriteria khusus, diantaranya merupakan anggota keluarga pasien kanker payudara baik dalam satu garis keturunan maupun di luar garis keturunan, secara aktif terlibat dalam perawatan pasien kanker payudara, berusia produktif, dan bersedia secara sukarela menjadi subjek penelitian.

Sesi intervensi ACT pada penelitian ini disusun berdasarkan modifikasi $A$ Toolkit Based on the Principles of Acceptance and Commitment Therapy oleh Jenkins dan Ahles (2019). Modul ini berdasar pada manual Acceptance and Commitment Therapy (ACT) oleh Hayes, Strosahl, dan Wilson (1999). Intervensi ini menekankan pada pembelajaran keterampilan baru secara singkat dalam menghadapi pikiran dan perasaan yang menyakitkan untuk mencapai fleksibilitas psikologis dan perilaku hidup yang lebih baik. Pada setiap akhir sesi diberikan skala untuk mengukur tingkat stres dan melihat perubahan kondisi subjek. Berikut adalah gambaran dari masing-masing sesi intervensi.

Sesi 1, pengantar dan diskusi permasalahan. Kepada subjek dijelaskan mengenai prosedur keseluruhan dari proses terapi, meliputi tujuan, kegiatan, waktu, dan durasi terapi. Pada sesi ini juga dijelaskan mengenai poin-poin dalam informed consent yang kemudian dapat 
disepakati bersama oleh peneliti dan subjek. Pada sesi ini, subjek diberi kesempatan untuk menceritakan pandangannya mengenai kondisi pasien. Subjek juga diminta untuk menceritakan situasi dan kondisi yang membuat subjek merasa tidak nyaman atau tertekan, kemudian mengidentifkasi respon yang muncul saat berada pada kondisi tersebut.

Sesi 2, mengenal dan menerima kondisi diri. Kepada subjek diberikan psikoedukasi mengenai stres, meliputi kondisi yang menyebabkan stres, ciri-ciri stres, dan dampak yang muncul akibat stres. Pada sesi ini subjek diminta untuk menjelaskan strategi koping yang dilakukan ketika berhadapan dengan situasi atau kondisi yang menimbulkan stres, kemudian mengidenti fikasi keefektifan dan pengaruh positif dari strategi koping tersebut.

Sesi 3, mindfulness and defusion. Subjek diberikan dua latihan untuk mengendalikan pikiran dan perasaan negatif yang muncul ketika berhadapan dengan sumber stres, yaitu worry box dan struggle switch. Pada sesi ini, subjek penelitian menuliskan hal-hal yang membuat mereka takut dan khawatir, serta halhal yang sudah dilakukan oleh subjek untuk meminimalkan perasaan negatifnya tersebut.

Sesi 4 , being present and observing self. Pada sesi ini subjek diajak untuk dapat lebih jujur terhadap diri sendiri mengenai kebutuhan diri, keinginan yang ingin dilakukan, dan keinginan yang ingin dicapai oleh diri. Pada sesi ini subjek juga diberikan praktik mindful breathing untuk melatih fokus dan pernapasan ketika berhadapan dengan sumber stres.

Sesi 5, values and committed action. Pada sesi ini subjek diajak untuk fokus pada arah hidup dengan lebih menerima dan memaknai setiap proses yang dihadapi dengan lebih positif. Lebih lanjut, subjek diajak untuk menyatakan komitmennya terhadap kegiatan saat ini serta menentukan langkah efektif untuk mencapai tujuan hidup. Pada sesi ini peneliti dan subjek bersama-sama mengevaluasi jalannya seluruh sesi dalam terapi dan mengambil kesimpulan serta pembelajaran dari hasil terapi yang telah dilakukan.

Konsep stres pada penelitian ini mengacu pada teori stres Lazarus dan Folkman (1984) yang menyatakan bahwa stres merupakan hasil dari hubungan individu dengan lingkungan yang kemudian dipersepsikan sebagai sesuatu yang melebihi kapasitas yang dimiliki atau mengancam kesejahteraan diri. Pada penelitian ini kuesioner digunakan sebagai alat pengumpulan data untuk mengukur tingkat stres pada subjek dengan menggunakan Perceived Stress Scale-10 (PSS-10) yang dirancang oleh Cohen, Kamarck, dan Mermelstein (1983). Cohen et al. (1983) membangun persepsi stres secara umum berdasarkan dua komponen, yaitu counter stress atau stres yang dapat dikendalikan dan perceived stress atau stres yang tidak dapat dikendalikan dan bersifat negatif. Perceived stress atau stres yang bersifat negatif kemudian disebutkan oleh Lazarus dan Folkman (1984) dengan distress. Cohen et al. (1983) merancang PSS-10 bertujuan untuk mengukur stres tidak spesifik yang dirasakan seseorang dalam situasi tertentu atau dalam kehidupan sehari-hari.

Lebih lanjut, skala ini terdiri atas tiga dimensi yaitu kejadian tidak terduga (unpredictable), kejadian tidak terkontrol (uncontrollable), dan kejadian yang melebihi kapasitas (overloading). Skala ini terdiri atas 10 butir dengan 6 butir favorable dan 4 butir unfavorable. Ada 5 pilihan alternatif jawaban, yaitu: tidak pernah, hampir tidak pernah, kadang-kadang, cukup sering, dan sangat sering. Kelima pilihan jawaban tersebut memiliki rentang nilai 0 sampai dengan 4. Skala PSS-10 yang telah diterjemahkan telah diuji reliabilitas oleh Arbi (2017) dan menunjukkan nilai reliabilitas 0,846 . Kategori stres berdasarkan hasil total skor skala PSS-10 adalah sebagai berikut: tinggi $(x>20,3)$, sedang $(7,1-20,3)$, rendah $(x<7,1)$.

Analisis data dilakukan dengan dua tahapan, yaitu analisis visual dan analisis inferensia menggunakan wilcoxon signed rank test untuk uji perbedaan dan uji effect size dengan Percentage of Non-Overlapping Data (PND). Analisis visual merupakan analisis data yang mengacu pada representasi garis grafik akurat dari pengukuran data pada fase baseline dan fase intervensi (Sunanto et al., 2005). Data tersebut diambil dari pengamatan pada fase baseline dan fase intervensi yang berbeda untuk menunjukkan pola, tingkat, dan kecenderungan perubahan perilaku secara jelas yang ditunjukkan oleh subjek.

Analisis selanjutnya dilakukan dengan menguji perbedaan menggunakan wilcoxon signed rank test untuk menganalisis perbedaan variabel pada dua kondisi subjek yang sama setelah dilakukan pengukuran secara berulang (Pallant, 2010). Selanjutnya, dilakukan uji effect size dengan PND. PND merupakan salah satu alternatif pengujian effect size yang dilakukan pada single case research design (Lenz, 2013). Scruggs dan Mastropieri (1998) menjelaskan 
bahwa metode non-overlap menghasilkan proporsi data dengan format desimal yang berkisar antara nol dan satu. Skor tersebut merupakan hasil pembagian antara jumlah data non-overlap dengan keseluruhan data pada fase intervensi. Skor yang lebih tinggi menunjukkan efek intervensi yang lebih besar sedangkan skor yang lebih rendah menunjukkan efek intervensi yang kurang. Selanjutnya, Scruggs dan Mastropieri (1998) mengategorikan nilai effect size menjadi empat kategori, yaitu efektivitas besar atau sangat efektif $(x>0,90)$, efektivitas sedang $(0,70-0,89)$, dan efektivitas masih diperdebatkan $(0,50$ $0,69)$, dan kurang efektif $(x<0,5)$.

\section{HASIL}

\section{Karakteristik Subjek Penelitian}

Subjek Pertama. Subjek pertama pada penelitian ini merupakan seorang ibu rumah tangga berusia 35 tahun dengan dua orang anak, anak pertama subjek berusia 4 tahun dan anak kedua subjek berusia 8 bulan. Sebelum menjadi caregiver, subjek bekerja sebagai penjaga kantin di salah satu sekolah SMA di Surabaya. Saat ini, subjek merawat pasien yang merupakan keponakannya berusia 17 tahun dengan kondisi pasca mastektomi atau pengangkatan payudara keseluruhan pada payudara kanan. Kondisi kesehatan pasien saat ini cukup baik dan mampu melakukan aktivitas sehari-hari dengan mandiri. Subjek berperan untuk menemani pasien melakukan kontrol rutin ke rumah sakit setiap 2-3 bulan sekali dan menyiapkan obat dan ramuan obat untuk dikonsumsi pasien secara rutin setiap hari.

Subjek mengambil peran sebagai caregiver karena kakek-nenek pasien sebagai pengganti orang tua pasien sudah tua dan tidak mampu melakukan perawatan terhadap pasien. Subjek mengeluhkan mengalami kelelahan karena harus mengurus dua orang anak, orang tua yang berusia lansia (kakek-nenek pasien), dan pasien. Selama proses intervensi, subjek tampak aktif dan kooperatif mengikuti seluruh rangkaian kegiatan. Setelah mengikuti terapi ACT, subjek menyatakan lebih tenang dan lega karena mampu mengeluarkan pikiran dan perasaan negatif yang selama ini dikeluhkan terutama berkaitan dengan proses perawatan pasien. Subjek mengaku dirinya menjadi lebih dekat dengan pasien, lebih berempati, dan memahami kejenuhan proses pengobatan yang dijalani pasien sehingga lebih peduli dan sabar dalam menghadapi pasien.
Subjek Kedua. Subjek kedua merupakan fresh graduate salah satu perguruan tinggi negeri di Surabaya, berusia 24 tahun dan berjenis kelamin perempuan. Subjek merupakan anak pertama dari tiga bersaudara. Subjek memiliki adik yang merupakan pelajar Sekolah Menengah Atas (SMA) dan Sekolah Menengah Pertama (SMP).

Subjek bekerja lepas (freelance) sebagai guru les. Subjek merawat ibunya yang harus menjalani perawatan paliatif (pasien mengalami metastase atau persebaran sel kanker di otak dan paru-paru). Saat ini pasien mengalami penurunan kondisi fisik sehingga harus dibantu ketika melakukan aktivitas seperti makan, minum, ke kamar mandi, dan lain-lain.

Subjek mengeluhkan jika dirinya saat ini mengalami kejenuhan, kelelahan, banyak pikiran, dan perasaan tertekan. Hal tersebut dikarenakan proses merawat pasien yang lebih intens sejak satu tahun terakhir. Kejenuhan tersebut menyebabkan subjek merasa takut pulang karena akan berhadapan kembali dengan rutinitasnya sebagai caregiver sehingga subjek sering menunda pulang setelah mengajar les untuk pergi nonton atau duduk di kafe seorang diri. Selama proses intervensi, subjek tampak aktif dan kooperatif mengikuti seluruh rangkaian kegiatan.

Hal tersebut menunjukkan bahwa subjek memiliki motivasi untuk bisa menurunkan stres dan tekanan yang dirasakannya. Setelah mengikuti terapi ACT, subjek menyatakan bahwa ia lebih ikhlas dan bisa menerima perannya sebagai caregiver. Subjek mengaku memiliki lebih banyak waktu berkualitas dengan pasien dibandingkan ketika pasien masih sehat. Situasi tersebut membuat subjek merasa dibutuhkan dan lebih dekat dengan pasien. Selain itu, subjek juga mengaku lebih dekat dengan adik-adiknya karena saling membantu dan bekerja sama dalam merawat pasien terutama ketika dirinya harus keluar rumah.

\section{Analisis Visual}

Analisis visual pada gambar 1 adalah perbandingan rata-rata tingkat stres subjek penelitian sebelum dan sesudah intervensi. Data menunjukkan terjadi penurunan nilai ratarata tingkat stres masing-masing subjek dari fase baseline $(A)$ dengan nilai rata-rata pada fase intervensi (B). Subjek 1 memiliki nilai ratarata stres 22,5 pada fase baseline (A) kemudian mengalami penurunan nilai rata-rata menjadi 16,25 pada fase intervensi (B). 


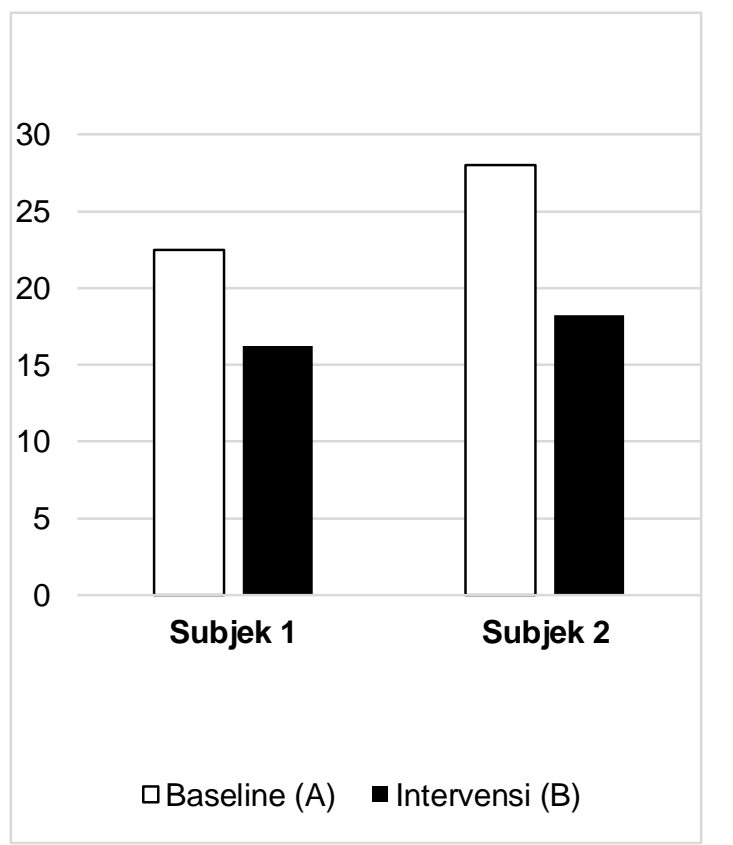

Gambar 1 Perbandingan rata-rata tingkat stres subjek

Berdasarkan pengategorian stres, tingkat stres subjek 1 pada fase baseline (A) termasuk dalam kategori stres level tinggi, kemudian mengalami penurunan pada fase intervensi (B) menjadi kategori stres level sedang. Hal ini mengindikasikan bahwa subjek 1 mengalami penurunan tingkat stres dari level tinggi menjadi level sedang setelah diberikan intervensi.

Penurunan level stres juga terjadi pada subjek 2. Hal tersebut diketahui karena subjek 2 memiliki nilai rata-rata stres 28 pada fase baseline (A) dan mengalami penurunan nilai rata-rata menjadi 18,25 pada fase intervensi (B). Berdasarkan pengategorian stres, pada fase baseline (A) subjek 2 termasuk dalam kategori stres level tinggi kemudian mengalami penurunan kategori stres pada fase intervensi (B) menjadi level sedang. Hal tersebut mengindikasikan bahwa subjek 2 mengalami penurunan tingkat stres setelah diberikan intervensi.

\section{Analisis Inferensia}

Tabel 1 Hasil uji perbedaan wilcoxon signed rank test

\begin{tabular}{|c|c|c|c|c|}
\hline $\begin{array}{c}\text { Hasil } \\
\text { uji }\end{array}$ & $\begin{array}{r}\text { Posttest } \\
1- \\
\text { Pretest2 }\end{array}$ & $\begin{array}{r}\text { Posttest } \\
2- \\
\text { Pretest2 }\end{array}$ & $\begin{array}{r}\text { Posttest } \\
3- \\
\text { Pretest2 }\end{array}$ & $\begin{array}{r}\text { Posttest } \\
4- \\
\text { Pretest2 }\end{array}$ \\
\hline Z & $-1,342^{a}$ & $-1,342^{a}$ & $-1,342^{a}$ & $-1,342^{a}$ \\
\hline $\begin{array}{l}\text { Asymp } \\
\text {. Sig. } \\
\text { (2- } \\
\text { tailed) }\end{array}$ & 0,180 & 0,180 & 0,180 & 0,180 \\
\hline
\end{tabular}

Tabel 2 Wilcoxon signed rank test

\begin{tabular}{lr}
\hline \multicolumn{2}{c}{ Pretest dan Posttest } \\
\hline$Z$ & $-1,604$ \\
Asymp. Sig. (2-tailed) & 0,109 \\
\hline
\end{tabular}

Tabel 1 adalah hasil uji perbedaan skor pretest dan posttest selama proses intervensi. Hasil uji statistik dengan wilcoxon signed rank test didapatkan nilai signifikansi sebesar $0,180>0,05$, yang berarti bahwa tidak terdapat perbedaan yang signifikan antara skor pretest dengan skor posttest. Hal ini mengindikasikan bahwa tidak terjadi perubahan stres yang signifikan pada family caregiver pasien kanker payudara setelah melakukan acceptance and commitment therapy.

Tabel 2 adalah nilai signifikansi (2-tailed) uji wilcoxon signed rank test secara keseluruhan dan menunjukkan nilai signifikansi sebesar $0,109>0,05$. Hal ini menunjukkan bahwa penerapan Acceptance and Commitment Therapy (ACT) tidak efektif untuk menurunkan stres pada family caregiver pasien kanker payudara.

Analisis berikutnya adalah melakukan uji effect size dengan teknik PND. Analisis ini bertujuan untuk melihat persentase data yang overlap dari masing-masing subjek dalam fase baseline (A) dan fase intervensi (B). Berikut ini adalah grafik PND berdasarkan indikator stres dari PSS-10 pada masing-masing subjek.

Unpredictable. Gambar 2 hasil visual grafik PND tentang persentase data yang overlap dari masing-masing subjek dalam fase baseline (A) dan fase intervensi (B) dengan indikator unpredictable menunjukkan hasil sebagai berikut. Pertama, seluruh data atau skor pada fase intervensi $(B)$ pada subjek 1 berada di bawah fase baseline $(\mathrm{A})$. Tidak terdapat data overlapping dari indikator unpredictable pada subjek 1 sehingga besaran nilai efektivitas subjek 1 pada indikator ini adalah 1. Oleh karena itu, dapat diartikan bahwa pemberian intervensi sangat efektif untuk menurunkan stres unpredictable pada subjek 1.

Kedua, grafik pada Gambar 2 tersebut juga menunjukkan seluruh data atau skor fase intervensi (B) pada subjek 2 berada di bawah fase baseline (A). Tidak terdapat data overlapping dari indikator unpredictable pada subjek 2 sehingga besaran nilai efektivitas subjek 2 pada indikator ini adalah 1. Dengan demikian, dapat diartikan bahwa pemberian intervensi juga sangat efektif untuk menurunkan stres unpredictable pada subjek 2. 


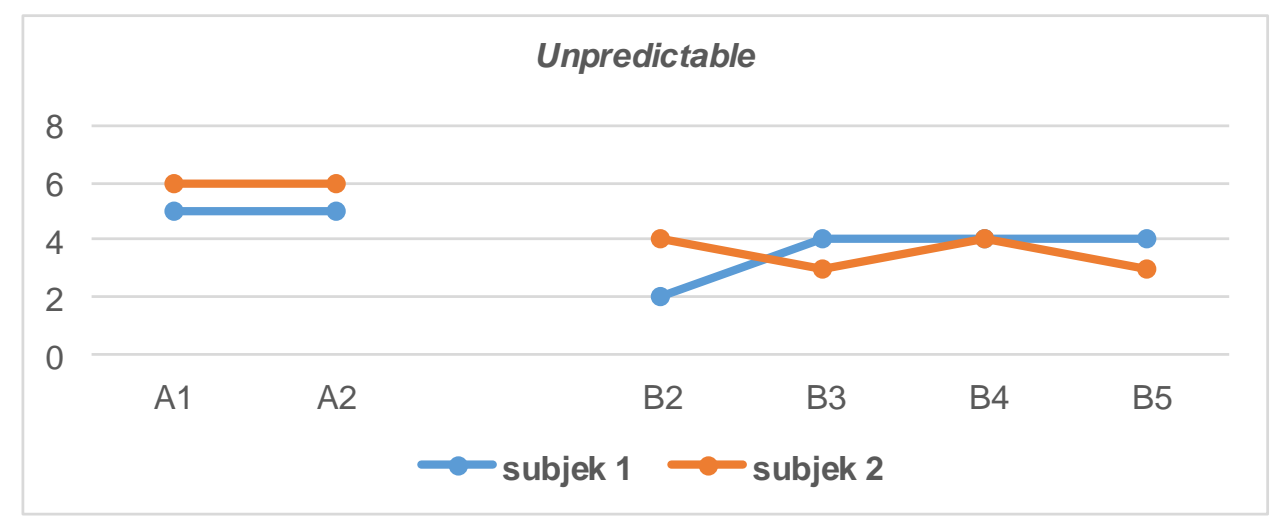

Gambar 2 Grafik PND indikator unpredictable

Uncontrollable. Gambar 3 hasil visual grafik PND tentang persentase data yang overlap dari masing-masing subjek dalam fase baseline $(A)$ dan fase intervensi (B) dengan indikator uncontrollable, menunjukkan hasil sebagai berikut. Pertama, skor fase intervensi (B) subjek 1 berada diatas fase baseline (A). Ada satu data overlapping dari indikator uncontrollable pada subjek 1 sehingga besaran nilai efektivitas subjek 1 adalah 0,75 . Dengan demikian, dapat diartikan bahwa pemberian intervensi memiliki efektivitas kategori sedang untuk menurunkan stres uncontrollable pada subjek 1. Kedua, grafik juga menunjukkan skor fase intervensi (B) pada subjek 2 berada dibawah fase baseline (A). Tidak terdapat data overlapping pada indikator uncontrollable pada subjek 2 sehingga besaran nilai efektivitas subjek 2 adalah 1 . Dengan demikian, dapat diartikan bahwa pemberian intervensi juga sangat efektif untuk menurunkan stres uncontrollable pada subjek 2 .

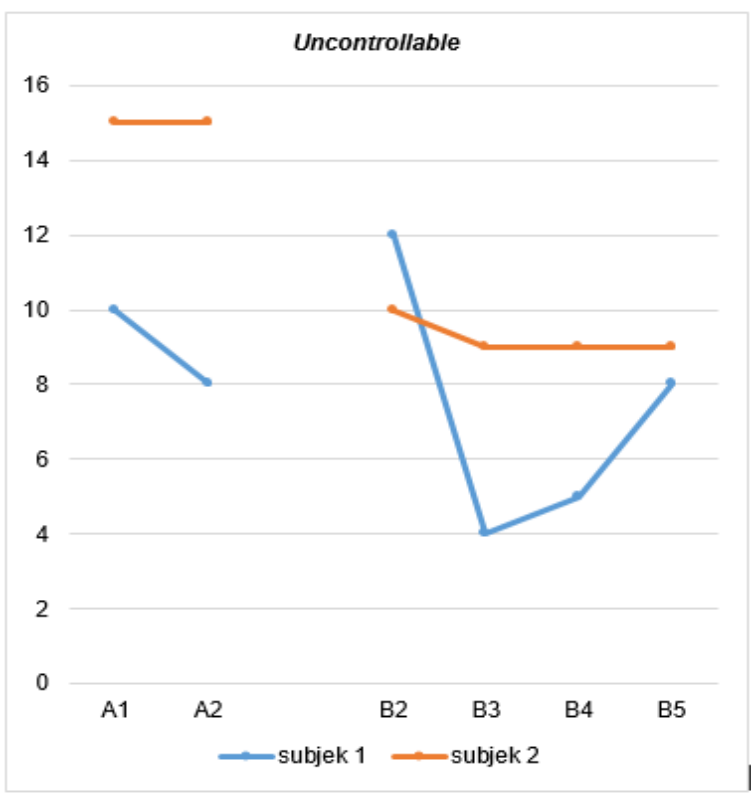

Gambar 3 Grafik PND indikator uncontrollable
Overloading. Gambar 4 hasil visual grafik PND tentang persentase data yang overlap dari masing-masing subjek dalam fase baseline $(A)$ dan fase intervensi (B) dengan indikator overloading, menunjukkan hasil sebagai berikut. Pertama, skor pada fase intervensi (B) subjek 1 berada dibawah fase baseline (A). Tidak terdapat data overlapping dari indikator overloading pada subjek 1 sehingga besaran nilai efektivitas adalah 1. Dengan demikian dapat diartikan bahwa pemberian intervensi sangat efektif untuk menurunkan stres overloading pada subjek 1. Kedua, grafik juga menunjukkan skor fase intervensi (B) subjek 2 berada dibawah fase baseline (A). Tidak terdapat data overlapping pada indikator overloading subjek 2 sehingga besaran nilai efektivitasnya adalah 1. Dengan demikian dapat diartikan bahwa pemberian intervensi juga sangat efektif untuk menurunkan stres overloading pada subjek 2 .

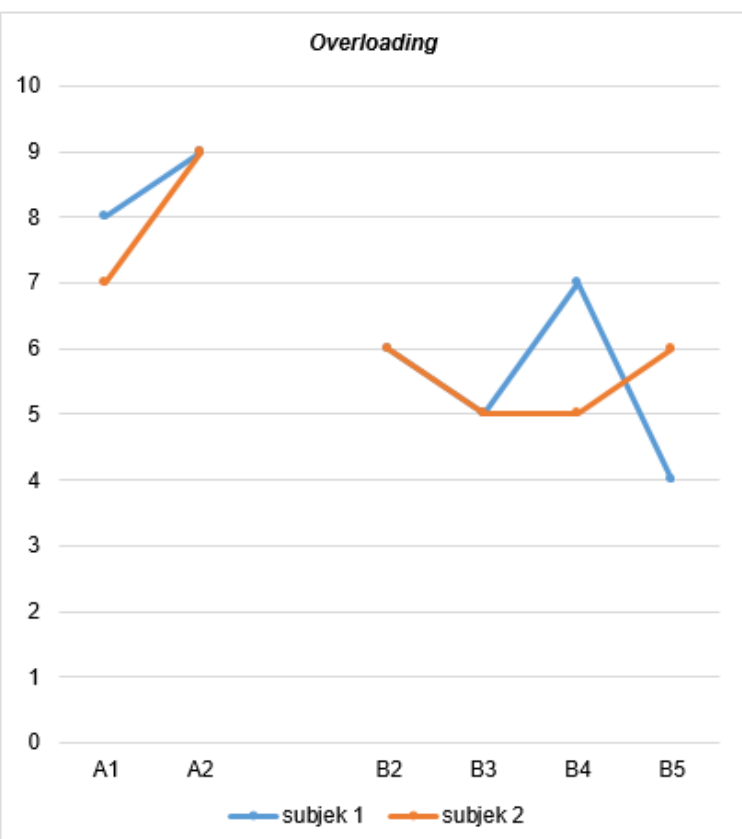

Gambar 4 Grafik PND indikator overloading 


\section{PEMBAHASAN}

Hasil penelitian menunjukkan bahwa Acceptance and Commitment Therapy (ACT) efektif untuk menurunkan stres pada family caregiver pasien kanker payudara. Hal ini dibuktikan dengan kecenderungan arah grafik menurun pada hasil analisis visual berdasarkan rata-rata skor dengan alat ukur PSS-10 pada masing-masing subjek (Gambar 1). Hasil analisis inferensia untuk menguji perbedaan dengan wilcoxon signed rank test menunjukkan nilai yang tidak signifikan sehingga penerapan ACT dinilai tidak efektif untuk menurunkan stres pada family caregiver pasien kanker payudara. Hasil uji perbedaan dengan wilcoxon signed rank test yang tidak signifikan dapat disebabkan oleh jumlah sampel penelitian yang terlalu kecil (Azwar, 2010). Sedangkan hasil uji efektivitas dengan Percentage of Nonoverlapping Data (PND) berdasarkan indikator stres yaitu unpredictable, uncontrollabel, dan overloading menunjukkan bahwa penerapan ACT memiliki efektivitas sedang hingga sangat efektif untuk menurunkan stres pada family caregiver pasien kanker payudara (Gambar 24).

Diagnosis kanker tidak hanya memengaruhi perubahan pada pasien, namun juga keluarga pasien. Ketika seseorang dalam keluarga menderita kanker, terjadi perubahan atau pergeseran peran dalam keluarga. Misalnya, ketika seorang istri menderita kanker, maka anak atau suami harus mengambil peran sebagai caregiver. Perubahan peran menjadi caregiver dapat mengurangi interaksi sosial karena fokus terhadap perawatan pasien dapat menyebabkan family caregiver merasa kurang memiliki dukungan sosial dan kesepian (Stenberg et al., 2010). Padahal dukungan sosial sangat dibutuhkan family caregiver. Schulz (2008) menjelaskan bahwa family caregiver yang mendapat dukungan sosial yang baik akan merasa lebih bahagia dan hidup lebih lama daripada family caregiver yang merasa terasing. Reaksi emosional muncul baik dari family caregiver maupun orang terdekat pasien kanker karena perubahan aktivitas menjadi seorang caregiver (Costa et al., 2016).

Acceptance and Commitment Therapy (ACT) efektif untuk menurunkan stres pada family caregiver pasien kanker payudara berdasarkan indikator stres yaitu unpredictable, uncontrollabel, dan overloading. Perubahan yang dirasakan masing-masing subjek setelah intervensi adalah dapat menerima situasi saat ini sebagai caregiver dan perubahan peran yang terjadi dalam keluarga dengan lebih positif. Subjek merasa memperoleh pengetahuan dan pengalaman baru terutama mengenai manajemen perawatan kanker payudara dan merasa lebih dekat serta lebih dibutuhkan oleh pasien. Hal ini sejalan dengan hasil penelitian Davis et al. (2019) bahwa ACT membantu caregiver untuk menerima pengalamannya serta mengatasi kesedihan dan tekanan psikologis yang dihadapi. Dengan penilaian pada pengalaman yang lebih positif terhadap perawatan pasien, family caregiver memiliki tingkat stres yang lebih rendah dan kualitas hidup yang lebih baik (Kim \& Schluz, 2008).

Pelaksanaan intervensi ACT dilakukan pada masing-masing subjek dengan kondisi dan situasi yang berbeda antar subjek. Subjek 1 mengalami kondisi dan situasi yang menyebabkan munculnya stres secara tidak langsung (stresor sekunder). Kondisi tersebut berkaitan dengan perannya sebagai ibu rumah tangga dengan dua orang anak yang salah satunya masih berusia balita. Dalam perannya mendampingi pengobatan pasien, subjek juga mengajak anaknya yang masih balita bersama karena subjek masih menyusui anaknya. Selain perannya sebagai ibu rumah tangga, subjek 1 juga memiliki peran untuk merawat kedua orang tua subjek yang berusia lansia. Situasi tersebut yang menyebabkan tugas pengasuhan dan perawatan terhadap pasien sepenuhnya dilakukan oleh subjek. Situasi dan kondisi lain yang menjadi sumber stres pada subjek 1 adalah berkaitan dengan kondisi psikologis pasien. Seperti diketahui pasien merupakan remaja berusia 17 tahun yang telah menjalani mastektomi atau pengangkatan payudara untuk mengurangi penyebaran sel kanker. Wanita yang telah menjalani mastektomi akan menilai diri negatif terhadap penampilannya dan merasa cemas terhadap penyakit yang mungkin belum hilang (Mahleda \& Hartini, 2012; Marguire \& Parkes, 1998). Kekhawatiran tersebut juga dirasakan oleh subjek sebagai family caregiver, namun subjek tetap berusaha untuk menguatkan dan memberikan semangat pada pasien.

Pada subjek 2 kondisi dan situasi menyebabkan munculnya stres secara langsung (stresor primer) dengan tambahan stresor sekunder. Pasien berada pada kondisi paliatif dan terjadi keterbatasan kemampuan fisik sehingga perawatan pasien lebih banyak dilakukan di rumah. Subjek 2 membantu aktivitas sehari-hari pasien, seperti membopong ke kursi roda untuk ke kamar mandi, memandikan atau menyeka, menyuapi, mengambilkan minum, memijat ketika pasien 
mengeluh sakit pada punggung, dan lain-lain. Subjek juga menyediakan transportasi untuk pasien kontrol ke dokter kemudian mengantarkannya pulang dan subjek harus pergi lagi ke apotek rumah sakit untuk membelikan resep obat. Subjek juga dihadapkan dengan kondisi psikologis pasien dalam menghadapi kematian. Seperti diketahui, kondisi pasien paliatif dengan dua kali mengalami metastase atau persebaran sel kanker di otak dan paru-paru. Kondisi paliatif menyebabkan pasien mengalami reaksi psikologis seperti denial atau menolak kondisinya, anger atau marah, bargaining atau tawar menawar terhadap situasi yang akan terjadi, depresi, dan acceptance (penerimaan) (Hartini, 2007). Selain itu, stresor sekunder yang dialami subjek adalah ketika pergeseran perannya sebagai anak menggantikan peran ibunya di rumah. Perbedaan individu dalam mempersepsi dan merespon stres dapat memengaruhi tingkat stres pada individu (Aguilo et al., 2017).

Intervensi ACT terbukti dapat menurunkan stres pada kedua subjek berdasarkan perubahanperubahan yang terjadi pada tiap sesi intervensi. Pada sesi pertama, subjek diminta untuk menyadari dan mengungkapkan kondisi yang membuat subjek merasa tertekan serta respon yang muncul. Proses ini membuat subjek lebih sadar mengenai kondisi stres yang memengaruhi dirinya. Saat berada pada kondisi sadar tersebut, subjek dapat mengevaluasi respon yang ditunjukkan dan memilih respon yang lebih adaptif dalam menghadapi stresor. Proses tersebut dijelaskan oleh Lazarus dan Folkman (1984) sebagai cognitive appraisal. Berdasarkan proses cognitive appraisal, terbentuk penilaian positif dari subjek terhadap perannya sebagai caregiver yang kemudian berpengaruh pada penurunan stres. Pada sesi kedua, subjek diberikan beberapa latihan yang bertujuan untuk mempertahankan fokus dan memperkuat kontrol diri dalam menghadapi pikiran dan perasaan negatif terkait pengalamannya. Latihan yang diberikan memiliki jenis yang berbeda. Pada "worry box" subjek diminta untuk menuliskan semua pikiran dan perasaan negatif yang dirasakan dan mengganggu. Aktivitas ini dilakukan untuk melatih subjek agar dapat lebih membuka diri dengan melakukan katarsis sehingga diharapkan beban pikiran subjek dapat tersalurkan melalui tulisan-tulisan yang dibuatnya. Hasil dari latihan ini adalah masingmasing subjek mampu menuliskan pikiran dan perasaan negatif yang dirasakannya selama ini. Berdasarkan hasil observasi, masing-masing subjek menunjukkan ekspresi fokus, mengernyitkan dahi, dan menghela napas panjang ketika menulis. Penelitian yang dilakukan Cash dan Lageman (2015) mengenai expressive writing pada family caregiver dan pasien penyakit parkinson menunjukkan bahwa expressive writing mampu memberikan perubahan positif terhadap kecemasan, depresi, dan beban pengasuhan. Latihan pada sesi ketiga yang diberikan adalah "struggle switch" yang fokus pada kemampuan kognitif subjek untuk mengelola pikirannya agar tidak terpengaruh pada pikiran dan perasaan negatif. Latihan ini bertujuan untuk memberikan keyakinan pada subjek bahwa pikiran dan perasaan negatif dapat dikendalikan oleh pikiran diri sendiri. Selanjutnya, latihan mindfull breathing juga diberikan sebagai latihan pernapasan, relaksasi, dan melatih fokus diri.

Sesi keempat, subjek diminta untuk mengungkapkan hal-hal positif yang dapat diambil dari pengalaman menjadi family caregiver pasien kanker payudara. Teknik ini bertujuan untuk memperkuat penerimaan dalam diri subjek. Penerimaan merupakan bagian penting dalam proses intervensi dengan ACT. Intervensi ACT berfokus untuk membangun penerimaan dan perhatian seseorang dalam menghadapi situasi saat ini sehingga terbentuk fleksibilitas psikologis dan memperkuat komitmen untuk menciptakan perubahan perilaku yang lebih adaptif (Hayes et al., 2011). Fleksibilitas psikologis merupakan kemampuan untuk berhadapan dengan situasi saat ini secara sadar dan penuh serta menunjukkan perilaku yang sesuai dengan nilai diri (Hayes et al., 2006). Hasil dari sesi ini adalah masing-masing subjek mampu membangun penerimaan dengan memaknai pengalamannya sebagai family caregiver dengan lebih positif, seperti menjadi lebih dekat dengan pasien, memiliki pengetahuan baru mengenai kanker payudara dan penanganannya, serta meningkatkan rasa syukur dalam diri atas semua hal yang telah dimiliki saat ini.

Pada sesi terakhir terapi, masing-masing subjek diminta untuk menjelaskan mengenai tujuan hidup yang ingin dicapai dan nilai-nilai diri yang mendasari perilaku dan tujuan tersebut. Sesi ini bertujuan membangun kepercayaan diri subjek mengenai kebermaknaan diri dan nilai diri untuk dapat menentukan tujuan hidupnya. Subjek juga diminta untuk menyatakan komitmennya dalam perawatan pasien dan rencana efektif yang akan dilakukan untuk mencapai tujuan hidup. Hasil dari sesi ini menunjukkan bahwa masingmasing subjek dapat membangun tujuan yang 
ingin dicapai berdasarkan nilai dirinya dan menyatakan komitmennya untuk terus memberikan yang terbaik dalam perawatan pasien. Keseluruhan proses tersebut kemudian ditemukan memengaruhi penurunan stres pada masing-masing subjek.

\section{SIMPULAN DAN SARAN}

Acceptance and commitment therapy efektif untuk menurunkan stres pada family caregiver pasien kanker payudara pada indikator stres unpredictable, uncontrollabel, dan overloading. Nilai efektivitas yang diperoleh tergolong pada kategori sedang hingga tinggi. Hasil intervensi menunjukkan bahwa family caregiver merasa dapat menilai situasi dengan lebih positif karena lebih dekat dengan pasien, merasa dibutuhkan oleh pasien, lebih dekat dengan anggota keluarga lain dengan saling bekerja sama merawat pasien, serta lebih menerima dan ikhlas menjalani perannya sebagai caregiver.

Rekomendasi selanjutnya adalah memperbesar jumlah subjek penelitian dan mempertimbangkan adanya variabel lain di luar variabel eksperimen yang dapat memengaruhi keberhasilan hasil penelitian. Berdasarkan hasil, dukungan keluarga atau orang terdekat dari family caregiver sangat dibutuhkan untuk mengurangi gejala stres yang muncul. Selain itu, tenaga kesehatan juga dapat memfasilitasi family caregiver untuk membuat support group agar dapat saling bertukar pengalaman termasuk pengetahuan dalam pengasuhan pasien kanker baik melalui media offline maupun online.

\section{DAFTAR PUSTAKA}

Aguilo, S., Barbeito, B., Garcia, E., \& Aguilo, J. (2017). Stress management in primary Caregivers: A health challenge. Society for Science and Education, 5(4), 558-564. doi:10.14738/tmlai.54.3292.

American Cancer Society. (2011). Breast cancer facts \& figures. Atlanta, ATL: American Cancer Society Inc.

Arbi, D. (2017). Efektivitas brief mindfulness based body scan therapy untuk menurunkan stres pada atlet bola basket wanita professional (Tesis). Surabaya, ID: Universitas Airlangga.

Azwar, S. (2010). Reliabilitas dan validitas. Yogyakarta, ID: Pustaka Pelajar.

Bevans, M. F., \& Sternberg, E. M. (2012). Caregiving burden, stress, and health effect among family caregivers of adult cancer patients. National Institutes of Health Public Access, 307(4), 398-403. doi:10.1001/jama.2012.29.

Borji, M., Nourmohammadi, H., Otaghi, M., Hosein, A., \& Tarjoman, A. (2018). Positive effect of cognitive behavioral therapy on depression, anxiety, and stress of family caregiver of patients with Prostate Cancer. Asian Pacific Journal Cancer, 18(12), 3207-3212. 18.12.3207.

Cantwell, P., Turco, S., Brenneis, C., Hanson, J., Neumann, C. M., \& Bruera, E. (2000). Predictors of home death in palliative care cancer patients. Journal of Palliative Care, 16, 23-28.

Cash, T., \& Lageman, S. (2015). Randomized controlled expressive writing pilot in individuals with parkinson's disease and their caregivers. Biomedical Central Psychology, 3(44), 1-12. doi:10.1186/s40359-015-0101-4.

Cassidy, T., \& McLaughlin, M. (2015). Psychological distress of female caregivers of significant others with cancer. Cogent Psychology, 2(999405), 1-12. doi:10.1080/23311908.2014.999405.

Cohen, S., Kamarck, T., \& Mermelstein, R. (1983). A global measure if perceived stress. Journal of Health and Social Behavior, 24(4), 385-396.

Collins, L. \& Swartz, K. (2011). Caregiver care. American Family Physician, 83(11), 13091317.

Costa, D. S., Bebber, R. M., Rutherford, C., Gabb, L., \& King, M. T. (2016). The impact of cancer on psychological and social outcomes. Australian Psychology Society, 51(2016), 89-99. doi:10.111/ap.12165.

Davis, E. L., Deane, F. P., \& Lyons, G. C. (2015). Acceptance and valued living as critical appraisal and coping strengths for caregivers dealing with terminal illness and bereavement. Palliative and Supportive Care, 13(2), 359-368. doi:10.1017/S1478951514000431.

Davis, E. L., Deane, F. P., \& Lyons, G.C. (2019). An acceptance and commitment therapy self-help intervention for carers of patients in palliative care: Protocol of a feasibility randomized controlled trial. Journal of Health Psychology, 24(5), 685704. doi: $10.1177 / 1359105316679724$. 
Family Caregiver Alliance. (2009). Caregiving. San Francisco, CA: National Center on Caregiving.

Harris, R. (2006) Embracing your demons: An overview of acceptance and commitment therapy. Psychotherapy in Australia, 12, 28.

Hartini, N. (2007). Dinamika pasien paliatif dalam menghadapi kematian. Media Insan Psikologi, 9(1), 69-80.

Hayes, S. C., Luoma, J. B., Bond, E. W., Masuda, A., \& Lilis, J. (2006). Acceptance and commitment therapy: Model, processes and outcomes. Georgia, ID: Georgia State University.

Hayes, S. C., Strosahl, K. D., \& Wilson, K. G. (1999). Acceptance and commitment therapy: An experiential approach to behavior change. New York, US: Guilford Press.

Hayes, S., Levin, M., Vilardaga, J., Villatte, J., \& Pistorello, J. (2011). Acceptance and commitment therapy and contextual behavioral science: Examining the progress of a distinctive model of behavioral and cognitive therapy. National Institute of Health, 44(2), 180-198. doi:10.1016/j.beth.2009.08.002.

Jenkins, J., \& Ahles, A. (2019). When the going get tough, the tough get mindful: $A$ toolkit based on the principles of acceptance and commitment therapy. Oklahoma, US: Family \& Children's Services.

[Kemenkes] Kementerian Kesehatan. (2020). Jenis Kanker ini Rentan Menyerang Manusia (online). Retrieved from http://sehatnegeriku.kemkes.go.id/baca/rili s-media/20200113/3432693/jenis-kankerrentan-menyerang-manusia/.

Kim, Y., \& Schulz, R. (2008). Family caregivers strains: Comparative analysis of cancer caregiving with dementia, diabetes, and frail elderly caregiving. Journal of Aging and Health, 20(5), 483-503, doi:10.1177/0898264308317533.

Kohle, N., Drossaert, H. C., Schreurs, K. M., Hagedoorn, M., Leeuw, I. M., \& Bohlmeijer, E. T. (2015). A web-based self-help intervention for partners of cancer patients based on acceptance and commitment therapy: A protocol of a randomized controlled trial. BMC Public Health, 15(303), 1-13, doi:10.1186/s12889-0151656-y.
Lazarus, R. S., \& Folkman, S. (1984). Stress: Appraisal and coping. New York, US: Springer.

Lenz, A. (2013). Calculating effect size in single-case research: A comparison of non-overlap methods. Measurement and Evaluation in Counseling and Development, 46(1), 64-73. doi: $10.1177 / 0748175612456401$.

Losada, A., Moreno, R., Lopez, J., Gonzalez, M., Mausbach, B., Fernandez, V., \& Gonzalez, C. (2015). Cognitive behavioral therapy (CBT) versus acceptance and commitment therapy (ACT) for demensia family caregivers with significant depressive symptoms: Results of a randomized clinical trial. Journal of Consulting and Clinical Psychology, 83(4), 760-772. doi:10.1037/ccp0000028.

Mahleda, M., \& Hartini, N. (2012). Posttraumatic growth pada pasien kanker payudara pasca mastektomi usia dewasa madya. Jurnal Psikologi dan Kesehatan Mental, 1(2), 67-71.

Marguire, P. \& Parkes, C.M. (1998). Coping with loss: Surgery and loss of body parts. BMJ Clinical Research, 316(7137), 1086. doi: 10.1136/bmj.316.7137.1086.

Neuman, W. (2006). Social research methods: Qualitative and quantitive approaches (7th ed.). New York, US: Pearson Education Inc.

Nijboer, C., Tempelaar, R., Sanderman, R., Triemstra, M., Spruijt, R., \& Van den bos, G, A. (1998). Cancer and caregiving: The impact on the caregiver's health. PsychoOncology, 7(1), 3-13. doi:10.1002/(SICl)1099-1611(199801/02).

Othman, N., Mahmud, Z., \& Karim, D. (2019). Family caregiver for cancer patients. Indian Journal of Public Health Research and Development, 10(6). 1-12, doi:10.5958/0976-5506.2019.01514.6.

Pallant, J. (2010). SPSS survival manual: $A$ step by step guide to data analysis using the SPSS program (4th Edition). New York, US: McGraw Hill.

Palos, G. R., Mendoza, T. R., Liao, K., Anderson, K., Gonzales, A., Hahn, K., Nazario, A., Ramondetta, L. M., Valero, V., Lynch, G., Weiss, J., \& Cleeland, C. (2010). Caregiver symptom burden: The risk of caring for an underserved patient with advanced cancer. Cancer, 117(5), 1070-1079. doi:10.1002/cncr.25695. 
Ramli, M. (2015). Update breast cancer management diagnostic and treatment. Majalah Kedokteran Andalas, 38(1), 28-53.

Riskind, J.H. \& Alloy, L. (2006). Cognitive vulnerability to psychological disorders: Overview of theory, design, and methods. Journal of Social and Clinical Psychology, 25(7), doi:10.1521/jscp.2006.25.7.705.

Scruggs, T., \& Mastropieri, M. (1998). Summarizing single-subject research: Issues and applications. Behavior Modification, 22(3), 221-242. doi:10.1177/01454455980223001.

Sercekus, P., Besen, D., Gunusen, N., \& Edeer, D. (2014). Experiences of family caregivers of cancer patients receiving chemotherapy. Asian Pacific Journal of Cancer Pervention, 15(12), 5063-5069. doi:10.7314/APJCP.2014.15.12.5063.

Soemitro, M. P. (2012). Blak-blakan kanker payudara. Bandung, ID: Mizan Pustaka.

Son, J., Erno, A., Shea, D., Femia, E., Zarit, S., \& Stephens, M. (2007). The cargiver stress process and health outcomes. Journal of Aging and Health, 19(6), 817-887. doi:10.1177/0898264307308568.

Stenberg, U., Ruland, C., \& Miaskowski, C. (2010). Review of the literature on the effect of caring for a patient with cancer. Psycho-Oncology, 19(10), 1013-1025. doi:10.1002/pon.1670.

Sunanto, J., Takeuchi, K., \& Nakata, H. (2005). Pengantar penelitian dengan subjek tunggal. Tsukuba, JP: Center for Research on International Coorporation in Educational Development (CRICED), University of Tsukuba.

Weitzner, M. A., Haley, W. E., \& Chen, H. (2000). The family caregiver of the older cancer patient. Oncology Clinics of North America, 14(1), 269-281. doi:10.1016/S0889-8588(05)70288-4.

[WHO] World Health Organization. (2019). Preventing Cancer (online). Retrieved from https://www.who.int/activities/preventingcancer. 